\title{
The locus coeruleus and cerebral metabolism: Recovery of function after cortical injury
}

\author{
DENNIS M. FEENEY, RICHARD L. SUTTON, MICHAEL G. BOYESON, \\ DAVID A. HOVDA, and WILLIAM G. DAIL \\ University of New Mexico, Albuquerque, New Mexico
}

\begin{abstract}
Cerebral metabolic effects of locus coeruleus (LC) lesion or drugs affecting LC were investigated after unilateral injury of sensorimotor cortex in rats. Sensoriomotor cortex ablation produced a widespread depression of cerebral ${ }^{14} \mathrm{C}$-2-deoxyglucose utilization which was reversed by amphetamine (AMP, $2 \mathrm{mg} / \mathrm{kg}$ ) and worsened by haloperidol (HAL, $0.4 \mathrm{mg} / \mathrm{kg}$ ). Lesion of LC alone did not affect cerebral oxidative metabolism, measured by a stain for the enzyme alphaglycerophosphate dehydrogenase ( $\alpha$-GPDH). Lesion of LC prior to undercut laceration of motor cortex shortened time to onset of $\alpha$-GPDH cortical paling. Treatment with AMP $(2 \mathrm{mg} / \mathrm{kg})$ blocked cortical paling of the enzyme stain at 4 days postinjury, an effect prevented by concomitant HAL ( 0.3 or $0.6 \mathrm{mg} / \mathrm{kg}$ ). Apomorphine $(1 \mathrm{mg} / \mathrm{kg})$ did not block cortical paling. These data parallel effects of these drugs on recovery of function. The results suggest that a metabolic "remote functional depression" (RFD) is alleviated by catecholamine activation after cortical injury, whereas onset of RFD is accelerated by LC lesions and exacerbated by catecholamine blockade.
\end{abstract}

The locus coeruleus (LC) may have an important role in neuronal development and plasticity (Felton, Hallman, \& Jonsson, 1982; Kasamatsu, Pettigrew, \& Ary, 1981; Parnavelus \& Blue, 1982). With its diffuse noradrenergic arborizations (Descarries, Watkins, \& LaPierre, 1977; Foote, Bloom, \& Aston-Jones, 1983), the LC may be involved in the development of the receptive fields of cat visual cortex neurons (Kasamatsu, Watabe, Scholler, \& Heggelund, 1983), although this is disputed (Daw, Videen, Parkinson, \& Rader, 1985). The LC has also been implicated in the environmental enrichment effect (O'Shea, Saari, Pappas, Ings, \& Stange, 1968). However, the role of the LC in classical learning is not yet clear (Amaral \& Sinnamon, 1977; Ögren, Archer, \& Ross, 1980; Wendlandt \& File, 1979). Like the neural developmental and enrichment effects, recovery of function after cortical injury, and maintenance of that recovery, may depend on the LC.

Drugs that influence LC activity have marked effects on recovery after cortical injury, but these drugs must be combined with relevant experience (EXP) during drug intoxication or no effect is obtained (cf. Braun, 1966; Braun, P. M. Meyer, \& D. R. Meyer, 1966; Ritchie, P. M.

M. G. Boyeson is currently with the Department of Rehabilitation, University of Wisconsin Medical School, Madison, WI 53792. D. A. Hovda is currently with the Mental Retardation Center, Neuropsychiatric Institute, UCLA, Los Angeles, CA 90024. W. G. Dail is with the Department of Anatomy, University of New Mexico, and D. M. Feeney and R. L. Sutton are with the Department of Psychology, University of New Mexico. Address correspondence to Richard L. Sutton, Department of Psychology, University of New Mexico, Albuquerque, NM 87131.
Meyer, \& D. R. Meyer, 1976). In rats (Feeney, Gonzalez, \& Law, 1982) or cats (Hovda \& Feeney, 1984) made hemiplegic by unilateral sensorimotor cortex ablations, an enduring acceleration of recovery is obtained with a single dose of amphetamine (AMP), but only if the animal is allowed to move about while intoxicated. This acceleration of recovery can be blocked by haloperidol (HAL), implicating catecholamines (CA) in the recovery process (Feeney et al., 1982). When given early after injury, HAL slows recovery of the hemiplegic rat, but again, only if locomotion is permitted during intoxication (Feeney et al., 1982). HAL affects both norepinephrine (NE) and dopamine (DA) (Bradshaw, Pun, Slater, Stoker, \& Szabadi, 1981), but only intraventricular NE, and not DA, reproduces the AMP plus EXP effect (Boyeson \& Feeney, 1984). Thus, NE projections of the LC may be important for recovery after cortical lesions.

The AMP/EXP regimen also restores some behaviors lost after cortical injury that would not be recovered otherwise. In cats with bilateral visual cortex ablations there is a complete and permanent loss of depth perception (Cornwell, Overman, Levitsky, \& Shipley, 1976), despite significant recovery of visual acuity (Kaye, Mitchell, \& Cynader, 1981). However, if such animals are given AMP after surgery there is an immediate restoration of depth perception, enduring for months after discontinuation of the drug treatment (Feeney \& Hovda, 1985). However, if the animals are housed in the dark for $24 \mathrm{~h}$ after AMP administration, no effect is obtained. The effect is also blocked by HAL (Hovda \& Feeney, 1985). In an extension of Feeney and Hovda's (1985) work, we found that the degree of recovery after bilateral visual cortex ablation may be influenced by asymmetry of lesions, and is 
less likely to occur in cats that fail to show signs of AMP intoxication (Hovda, Sutton, \& Feeney, 1985).

The AMP/EXP treatment does not promote recovery of locomotion after unilateral cerebellar hemisphere ablations (Boyeson \& Feeney, 1984), suggesting that the treatment effect may be limited to cerebral cortex or forebrain injury deficits. This may implicate the cerebellum $(\mathrm{Cb})$ in the AMP/EXP promotion of recovery, since the treatment regimen alters $\mathrm{NE}$ turnover in the $\mathrm{Cb}$ of motorcortex ablated rats (Boyeson \& Feeney, 1984). The LC innervation of the $\mathrm{Cb}$ is implicated in motor learning (Watson \& McElligott, 1984) and may also be involved in depth perception (Feeney \& Hovda, 1985). The contralateral sensorimotor cortex is not necessary for the AMP/EXP effect on recovery from hemiplegia, since the treatment effect is obtained in cats with extensive bilateral frontal ablations (Sutton, Hovda, \& Feeney, 1984), suggesting that recovery is mediated by a subcortical structure such as the $\mathrm{Cb}$.

Undoubtedly, many factors could be involved in recovery after cortical injury (for a review, see Finger \& Stein, 1982). However, the physiological basis for the AMP/EXP data is most compatible with the concept of a "remote functional depression" (RFD) after cortical injury. The proposal of RFD implies that measurable changes in some spared brain areas would be reflected in reduced neuronal activity and/or metabolism. Depressed metabolism has been reported in the $\mathrm{Cb}$ remote from areas of supratentorial tumors (Patronas et al., 1984) and strokes (Kurshner et al., 1984), but these were correlational observations.

One way to test the RFD hypothesis is to determine whether manipulations influencing behavioral recovery after brain injury also influence measures of cerebral metabolism. We have used two measures of cerebral metabolism, ${ }^{14} \mathrm{C}$-2-deoxyglucose (2-DG) and the histochemical stain for the oxidative enzyme alphaglycerophosphate dehydrogenase ( $\alpha$-GPDH). Our data indicate that the widespread depression of oxidative metabolism after cortical injury, revealed by the $\alpha$-GPDH stain (Dail, Feeney, Murray, Linn, \& Boyeson, 1981), is influenced by lesions of the LC as well as by drug manipulation known to alter LC single-unit activity and to affect behavioral recovery. Preliminary results were presented as abstracts (Dail, Boyeson, Feeney, \& Murray, 1981; Feeney, Rodriguez, Hovda, \& Boyeson, 1984).

\section{EXPERIMENT 1}

\section{Method}

Subjects. Ten male Sprague-Dawley rats (Harlan-Gibco) weighing from 275 to $315 \mathrm{~g}$ were used as subjects. Animals were housed in individual cages and maintained on a 12-h/12-h light/dark cycle, with food and water available ad lib.

Procedure. Surgical procedures for inducing suction ablation of the right sensorimotor cortex in 6 rats were performed as previously described (Feeney et al., 1982). Saline (SAL, $n=2)$, HAL $(0.4 \mathrm{mg} / \mathrm{kg}, \mathrm{n}=2)$ or AMP $(2 \mathrm{mg} / \mathrm{kg}, \mathrm{n}=2)$ was administered in- traperitoneally (ip) $24 \mathrm{~h}$ postinjury and animals were returned to their home cages.

Autoradiography procedures were adapted from those described by Sokoloff et al. (1977). Briefly, the 6 injured animals and 4 normal, uninjured rats were administered ${ }^{14} \mathrm{C}$-2-DG $(50 \mu \mathrm{Ci}$, ip) $24 \mathrm{~h}$ after drug treatment. Animals were sacrificed by decapitation $45 \mathrm{~min}$ after 2-DG administation and the brains were quickly removed. Histological sections were cut at $20 \mu \mathrm{m}$ on a cryostat at $-20^{\circ} \mathrm{C}$ and were mounted onto glass microscope slides. Sections were then autoradiographed with Kodak SB-5 x-ray film for 5 days. The exposed film images were color-enhanced using a VAX 11/780 computer interfaced with a COMTAL image processing unit. Final color images were obtained using a Matrix Instrument Model 3000.

\section{Results}

The results from SAL-treated injured animals indicated a widespread depression of glucose utilization (Figure 1A) compared to that of normal controls (Figure 1B). The most affected areas included the contralateral and ipsilateral cortices, the ipsilateral red nucleus, and the LC. AMP dramatically reversed this metabolic depression throughout the cortical areas (Figure 1C) and brain stem of injured animals, whereas HAL worsened glucose utilization, particularly in the cerebellum and brain stem. Most importantly, like the behavioral effects on recovery of function in brain-damaged animals, the effect of AMP was enduring: it alleviated the depressed ${ }^{14} \mathrm{C}-2-\mathrm{DG}$ uptake $24 \mathrm{~h}$ after administration, at a time when the drug would have been metabolized.

\section{EXPERIMENT 2}

Twenty-two male Sprague-Dawley rats were used in this experiment. Housing conditions, light/dark schedule, and access to food and water were the same as for subjects in Experiment 1.

In this experiment, we investigated the effects of undercut laceration of the hindpaw area of the right motor cortex of rats and the effects of unilateral (right) radiofrequency lesions of the LC and various drug manipulations on the $\alpha$-GPDH staining pattern. Surgical procedures used for the cortical injury and the histochemical methods used are described in Dail, Feeney, Murray, Linn, \& Boyeson (1981). The LC lesions were induced at coordinates AP -1.7 , LAT 1.3, VERT +2.4 relative to the interaural plane, with the incisor bar elevated $1 \mathrm{~mm}$. Current was slowly increased to $14 \mathrm{~mA}$ and was maintained for $2 \mathrm{~min}$, using insulated electrodes bared $0.5 \mathrm{~mm}$ at the tip. All drugs were administered ip.

To directly determine if the LC is involved in the oxidative enzyme staining pattern of the lesioned cortex, we studied only rats with unilateral LC lesions. In 6 animals, the right LC was lesioned without inducing a cortical injury; this did not affect $\alpha$-GPDH staining at 1 day $(n=2)$ or 4 days $(n=4)$ postlesion. Additional animals $(n=5)$ received lesions of the right $L C$ followed in 2 weeks by an undercut of the right motor cortex. These 5 rats were sacrificed $12 \mathrm{~h}$ after cortical injury. Histochemical analysis revealed that no paling of the $\alpha$-GPDH stain occurred at $12 \mathrm{~h}$ postundercut if the LC was intact $(n=3$; these le- 

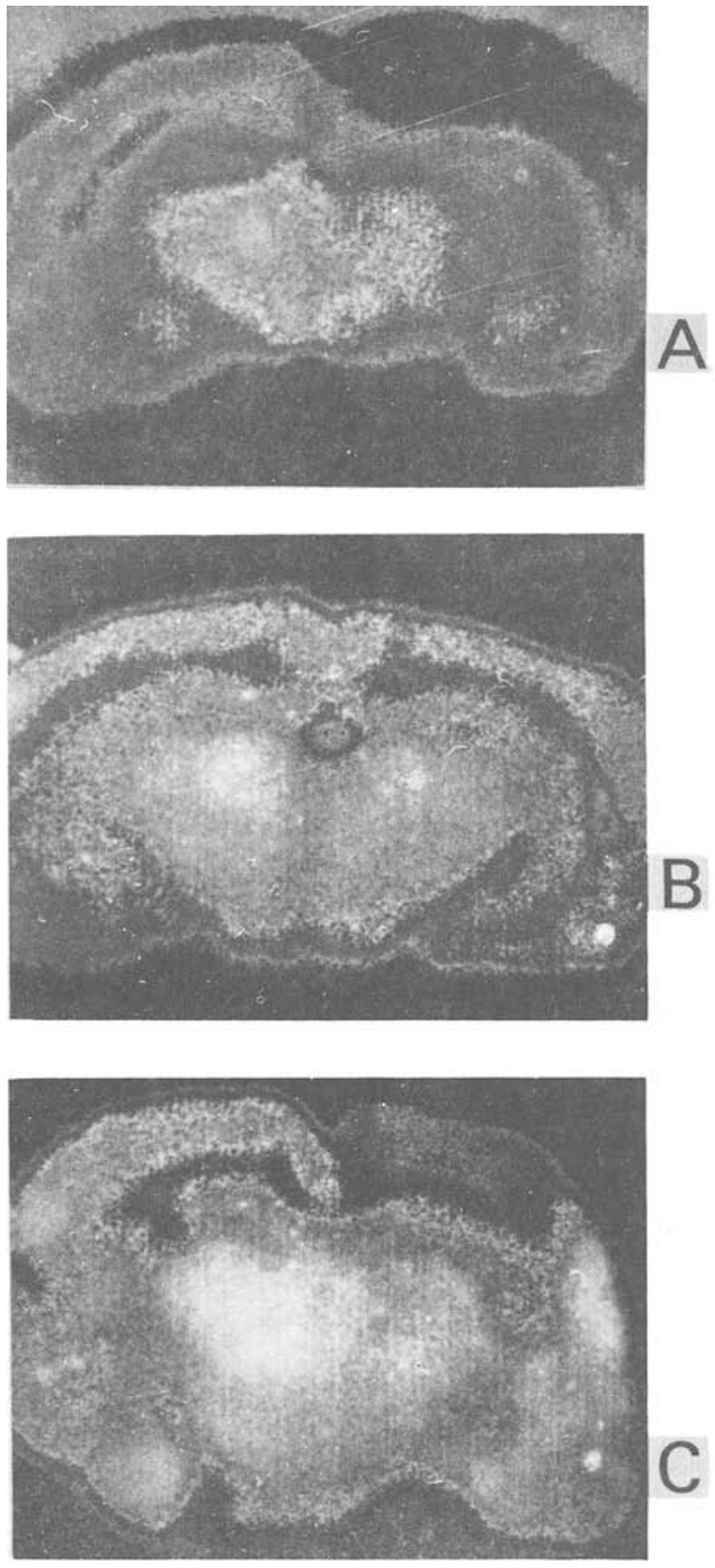

Figure 1. These are black-and-white photographs of computerenhanced color images of autoradiographs. Darker regions indicate low glucose utilization, whereas lighter regions indicate higher metabolic activity. (A) ${ }^{14} \mathrm{C}$-2-deoxyglucose (2-DG) utilization $48 \mathrm{~h}$ after unilateral sensorimotor cortex ablation in a saline-treated animal. Note darkened cortex ipsilateral (right) and contralateral (left) to injury, indicating widespread reduction of 2-DG uptake and metabolism. This section was taken approximately $0.5 \mathrm{~mm}$ posterior to ablation. (B) 2-DG utilization in an uninjured rat. This section was taken at approximately $1.5 \mathrm{~mm}$ posterior to bregma. (C) 2-DG utilization $48 \mathrm{~h}$ after unilateral sensorimotor cortex ablation in an amphetamine $(2 \mathrm{mg} / \mathrm{kg}$ )-treated animal. Note the increased 2-DG uptake throughout cortical and subcortical areas as compared with the saline-treated animal, indicating that amphetamine is alleviating a widespread metabolic depression. This section was taken approximately $0.5 \mathrm{~mm}$ posterior to injury.

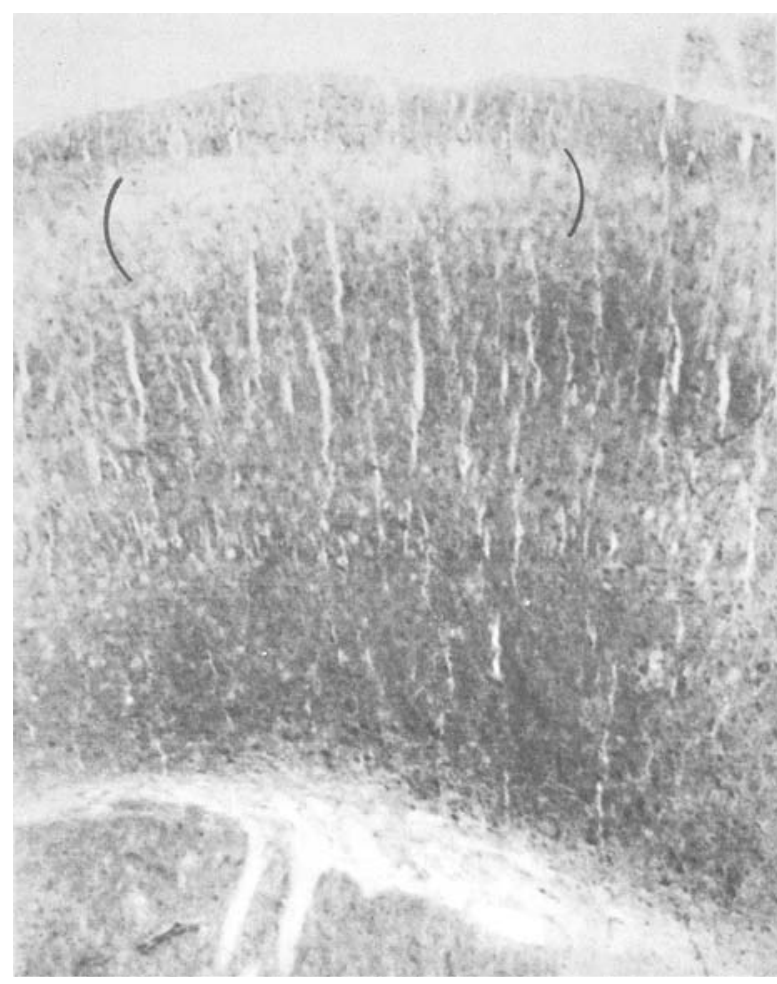

Figure 2.Alpha-glycerophosphate dehydrogenase activity in the cerebrum of a rat with a unilateral lesion of the locus coeruleus, followed in 2 weeks by an undercut laceration of motor cortex. The animal was sacrificed at $12 \mathrm{~h}$ postundercut. Note the virtual absence of stain in cortical layers 2 and 3 (between parentheses).

sions were in the inferior colliculus, fourth ventricle, or cerebellum). In the case of a lesion encompassing both the parvocellular and magnocellular portions of the LC, complete paling of the enzyme was evident $(n=1$; see Figure 2); a lesion of the parvocellular region alone resulted in partial paling of the enzyme stain at $12 \mathrm{~h}$ postundercut $(n=1)$. These results indicate that the time to onset of metabolic disturbances following cortical injury is shortened by LC lesions. The earliest we have seen cortical paling following cortical injury alone is $36 \mathrm{~h}$ (Dail, Feeney, Murray, Linn, \& Boyeson, 1981).

To examine the effects of CA agonists and antagonists on $\alpha$-GPDH activity in the injured brain, we administered an undercut injury to the right motor cortex of 11 rats, followed in $24 \mathrm{~h}$ by drug administration. Brain tissue was removed and stained for $\alpha$-GPDH activity at 4 days postinjury.

Treatment with AMP ( $2 \mathrm{mg} / \mathrm{kg}$ ) prevented depression of enzyme staining in the cortex of the injured hemisphere in 2 out of 3 animals, whereas a lower dose of AMP $(1 \mathrm{mg} / \mathrm{kg}, \mathrm{n}=2)$ did not block paling of the enzyme stain.

Additional animals with laceration injury were given AMP $(2 \mathrm{mg} / \mathrm{kg})$ immediately followed by $\mathrm{HAL}$ $(0.3 \mathrm{mg} / \mathrm{kg}, \mathrm{n}=2 ; 0.6 \mathrm{mg} / \mathrm{kg}, \mathrm{n}=2)$. In all cases, the administration of HAL blocked the AMP-induced prevention of cortical paling of the enzyme stain. In animals 
given the DA agonist apomorphine $(1 \mathrm{mg} / \mathrm{kg}, \mathrm{n}=2)$, there was no prevention of cortical paling of the enzyme. These data suggest that the CA, most likely NE, affect the RFD that occurs following cortical insult.

\section{DISCUSSION}

These results indicate that reduced noradrenergic functioning may exacerbate or accelerate the development of metabolic depression after focal cortical injury. This suggests that the AMP/EXP treatment, which promotes recovery after cortical injury, may affect behavior by alleviating a widespread cerebral metabolic RFD. Our finding that unilateral LC lesions alone did not alter cerebral oxidative metabolism is similar to the finding of Savaki, Graham, Grome, and McCulloch (1984), who reported that unilateral LC lesions had little or no effect on 2-DG utilization in rats. However, LaManna, Harik, Light, and Rosenthal (1981) reported that although depletion of NE does not change "resting" metabolic activity in the cerebral cortex, it does alter the increased oxidative metabolism evoked by electrical stimulation of the cortex. Their finding is similar to that reported here: LC lesions alter the metabolic response to subsequent cortical laceration.

We have previously noted that our AMP/EXP data are compatible with the theory of diaschisis (Feeney et al., 1982; Hovda \& Feeney, 1984). Diaschisis can be translated as "shocked throughout." According to this theory, formulated by von Monakow (1914/1969), some of the symptoms of brain damage result from a transient shock to brain regions remote from, but connected to, the area of primary damage. As the hypothesized shock dissipates with time, lost behaviors influenced by these areas recover. As first postulated, diaschisis was circularly defined and provided no mechanism by which the functional shock could be measured. Therefore, we prefer the more specific and descriptive term RFD as a modern revision of part of the concept of diaschisis. Although von Monakow's theory of diaschisis has been supported (Kempinsky, 1958; cf. P. M. Meyer \& D. R. Meyer, 1982), refuted (West, Deadwyler, Cotman, \& Lynch, 1976), and debated (Markowitsch \& Pritzel, 1978; West, 1978), modern techniques are beginning to supply data that will allow us to firmly anchor the concept of diaschisis and escape the circularity of definition. There is now ample evidence that a RFD of CA occurs after cortical injury. Reduced brain CA levels and turnover after stroke or brain trauma have been reported in several species (Boyeson \& Feeney, 1984, 1985; Cohen, Waltz, \& Jacobson, 1975; Kogure, Scheinberg, Matsumoto, Busto, \& Reinmuth, 1975; Robinson, 1979; Robinson \& Bloom, 1977; Robinson \& Coyle, 1979, 1980; Robinson, Shoemaker, \& Schlumpf, 1980; Robinson, Shoemaker, Schlumpf, Valk, \& Bloom, 1975; Zervas et al., 1974). These altered CA levels following cortical injury may result from damage to $\mathrm{CA}$ axons, producing a shift from transmitter production to protein synthesis for repair
(Ross, Joh, \& Reis, 1975). Evidence for RFD after injury to the brain is also provided by several histochemical studies (Cooper, Thurlow, \& Rooney, 1984; Dail, Feeney, Murray, Linn, \& Boyeson, 1981; Frey \& Agranoff, 1983; Pappius \& Wolfe, 1983; Reinstein, Isaacson, \& Dunn, 1979; Schwartz, Sharp, Gunn, \& Evarts, 1976) and by studies employing electrophysiological techniques (Glassman, 1970; Glassman \& Malamut, 1976; Kempinsky, 1954, 1956, 1958; Pittman, Feeney, \& Spiker, 1976).

We propose that after cortical injury pharmacological stimulation of the LC may "enable" (Moore \& Bloom, 1979) some functionally depressed neural systems to respond to environmental stimulation (i.e., EXP), alleviating a CA and metabolic RFD and allowing behavioral symptoms to abate. Subsequent to the pioneering work of Maling and Acheson (1946), many studies have suggested the importance of CA activation in recovery after brain injury, with AMP reportedly enhancing recovery following injury to the sensorimotor and/or visual systems (Amassian, Ross, Wertenbaker, \& Weiner, 1972; Beattie, Gray, Rosenfeld, P. M. Meyer, \& D. R. Meyer, 1978; Boyeson \& Feeney, 1984; Braun, 1966; Braun et al., 1966; Cole, Sullins, \& Isaac, 1967; Feeney et al., 1982; Feeney \& Hovda, 1983, 1985; Glick, 1974; Glick \& Zimmerberg, 1978; Hovda \& Feeney, 1984, 1985; Jonason, Lauber, Robbins, P. M. Meyer, \& D. R. Meyer, 1970; Macht, 1950; P. M. Meyer, Horel, \& D. R. Meyer, 1963; Ritchie et al., 1976; Sechzer, Ervin, \& Smith, 1973; Sutton et al., 1984) or following lesions of the septal nuclei (Marotta, Logan, Potegal, Glusman, \& Gardner, 1977).

The role of CA agonists in recovery must be modulatory, because it would be impossible for the CA somata in the brain stem to take over the functions of such diverse structures as the motor cortex, visual cortex, and septal nuclei, thereby alleviating various behavioral consequences of injury to these areas. Rather, the proposed regulation of cerebral tone or signal-to-noise ratio for NE (Amaral \& Sinnamon, 1977; van Dongen, 1981) and sensorimotor integration for DA (Feeney \& Weir, 1979) is more compatible with the data. The widespread arborizations of the LC axons throughout the cerebral cortex, cerebellum, and lateral tegmental system to brain stem, spinal cord, and hypothalamus would represent an anatomy expected of the hypothesized enabling system (for a review, see Foote et al., 1983). Studies using a variety of techniques have demonstrated that axons from the LC bifurcate and simultaneously innervate forebrain, cerebellar, and/or spinal areas (Crawley, Maas, \& Roth, 1980; Nakamura \& Iwama, 1975; Olson \& Fuxe, 1971; Room, Postema, \& Korf, 1981; Steindler, 1981). Finally, the LC may have an integrative function, since it receives afferents from diverse areas of the brain known to respond to internal and external stimulation (Foote et al., 1983).

Although CA agonists have proven beneficial after brain injury, recovery is vulnerable and may depend on adrenergic compensation. The maintenance of recovery after 
unilateral motor cortex injury appears to depend on the integrity of the alpha adrenergic system; a single dose of the alpha-adrenergic antagonist phenoxybenzamine (PBZ) given to cats (Hovda, Feeney, Salo, \& Boyeson, 1983) or rats (Boyeson \& Feeney, 1984) recovered from sensorimotor cortex lesions dramatically reinstated sensory and motor deficits just as they appeared immediately after injury. The same dose of PBZ had only a mild soporific effect in normal cats and rats. Neither HAL nor propranolol (PROP) reinstated deficits in the recovered animals. Other investigators have found that PBZ increases the incidence of stroke, worsens neurological symptoms, and causes high mortality in an experimental stroke model (McGraw, Pashyan, \& Wendell, 1976). Additionally, a clinical study with ischemic or infarcted patients reported that a combined treatment with PBZ and PROP worsened neurological deficits in some patients (J.

S. Meyer et al., 1976).

The studies cited above may have important implications for the treatment of stroke and trauma patients (cf. D. R. Meyer \& Beattie, 1977; P. M. Meyer \& D. R. Meyer, 1982). In one uncontrolled study, AMP enhanced recovery when given to geriatric patients (some with stroke) refractory to rehabilitation, and, significantly, the recovery endured after discontinuation of AMP (Clark \& Mankikar, 1979). Two case reports also describe AMPinduced behavioral improvement after trauma (Bugiani \& Gatti, 1980; Lipper \& Tuchman, 1976). Moreover, a retrospective study of the rate of recovery from aphasia after stroke indicated that thiazides or alpha blockers, especially HAL, slowed recovery compared to recovery of undrugged patients or those given PROP (Porch, Wyckes, $\&$ Feeney, 1985). Since PROP can successfully manage aggressive patients (Greendyke, Schuster, \& Wooton, 1984), this drug would be preferable to HAL, which is often administered to agitated brain-injured patients (Cowley \& Glen, 1979; Smith, Taylor, \& Linkous, 1974). Because there is currently no effective treatment to promote recovery from brain injury, and some drugs currently in use may be harmful, this area clearly requires both clinical and basic science investigations. ${ }^{1}$

\section{REFERENCES}

Amaral, D. G., \& Sinnamon, H. M. (1977). The locus coeruleus: Neurobiology of a central noradrenergic nucleus. Progress in Neurobiology, 9, 147-196.

amassian, V. E., Ross, R., Wertenbaker, C., \& Weiner, H. (1972). Cerebellothalamocortical interrelations in contact placing and other movements in cats. In T. Frigyesi, E. Rinvik, \& M. D. Yahr (Eds.), Corticothalamic projections and sensorimotor activities (pp. 395-444). New York: Raven Press.

Beattie, M. S., Gray, T. S., Rosenfeld, J. A., Meyer, P. M., \& MEYER, D. R. (1978). Residual capacity for avoidance learning in decorticate rats: Enhancement of performance and demonstration of latent learning with d-amphetamine treatments. Physiological Psychology, 6, 279-287.

BlomQvist, P., Lindvall, O., \& Wieloch, T. (1985). Lesions of the locus coeruleus system aggravate ischemic damage in the rat brain. Neuroscience Letters, 58, 353-358.
Boyeson, M. G., \& FeEnEy, D. M. (1984). The role of norepinephrine in recovery from brain injury. Society for Neuroscience Abstracts, 10, 68.

Boyeson, M. G., \& FeEneY, D. M. (1985). Striatal dopamine after cortical injury. Experimental Neurology, 89, 479-483.

Bradshaw, C. M., Pun, R. Y. K., Slater, N. T., Stoker, M. J., \& SzABADI, E. (1981). Comparison of the effect of haloperidol on excitatory responses of cortical neurones to dopamine, noradrenaline, and phenylephrine. British Journal of Pharmacology, 73, 243-244.

BraUn, J. J. (1966). The neocortex and visual placing in rats. Brain Research, 1, 381-394.

Braun, J. J., Meyer, P. M., \& Meyer, D. R. (1966). Sparing of a brightness habit in rats following visual decortication. Journal of Comparative \& Physiological Psychology, 61, 79-82.

BUGIANI, O., \& GATTI, R. (1980). L-dopa in children with progressive neurological disorders. Annals of Neurology, 7, 93.

Clark, A. N. G., \& Mankikar, G. D. (1979). D-amphetamine in elderly patients refractory to rehabilitation procedures. Journal of the American Geriatrics Society, 27, 174-177.

Cohen, H. P., Waltz, A. G., \& JaCobson, R. L. (1975). Catecholamine content of cerebral tissue after occlusion or manipulation of middle cerebral artery in cats. Journal of Neurosurgery, 43, 32-36.

Cole, D. D., Sullins, W. R., \& IsaAC, W. (1967). Pharmacological modifications of the effects of spaced occipital ablations. Psychopharmacologia, 11, 311-316.

Cooper, R. M., Thurlow, G. A., \& Rooney, B. J. (1984). 2Deoxyglucose uptake and histological changes in rat thalamus after neocortical ablations. Experimental Neurology, 83, 134-143.

Cornwell, P., Overman, W., Levitsky, C., \& ShiPley, J. (1976). Performance on the visual cliff by cats with marginal gyrus lesions. Journal of Comparative \& Physiological Psychology, 90, 996-1010.

Cowley, L. M., \& GLEN, R. S. (1979). Double-blind study of thioridazine and haloperidol in geriatric patients with a psychosis associated with organic brain syndrome. Journal of Clinical Psychiatry, 40, 411-419.

Crawley, J. N., MaAs, J. W., \& Roth, R. H. (1980). Biochemical evidence for simultaneous activation of multiple locus coeruleus efferents. Life Sciences, 26, 1373-1378.

Dail, W. G., Boyeson, M. G., Feeney, D. M., \& Murray, H. M. (1981). Evidence for a role for catecholamines in the hemisphereic changes in the activity of a brain enzyme following a local cortical injury. Society for Neuroscience Abstracts, 7, 572.

Dail, W. G., Feeney, D. M., Murray, H. M., LinN, R. T., \& Boyeson, M. G. (1981). Responses to cortical injury: II. Widespread depression of the activity of an enzyme in cortex remote from a focal injury. Brain Research, 211, 79-89.

Daw, N. W., Videen, T. O., Parkinson, D., \& RADER, R. K. (1985). DSP-4 (N-(2-chloroethyl)-N-ethyl-2-bromobenzylamine) depletes noradrenaline in kitten visual cortex without altering the effects of monocular deprivation. The Journal of Neuroscience, 5, 1925-1933.

Descarries, L., Watkins, K. C., \& LAPierre, Y. (1977). Noradrenergic axon terminals in the cerebral cortex of rats. III. Topometric ultrastructural analysis. Brain Research, 133, 197-222.

FeEney, D. M., Gonzalez, A., \& LAW, W. A. (1982). Amphetamine, haloperidol and experience interact to affect rate of recovery after motor cortex injury. Science, 217, 855-857.

FeENEY, D. M. , \& HovdA, D. A. (1983). Amphetamine and apomorphine restore tactile placing after motor cortex injury in the cat. Psychopharmacology, 79, 67-71.

FEENEY, D. M., \& HovdA, D. A. (1985). Reinstatement of binocular depth perception by amphetamine and visual experience after visual cortex ablation. Brain Research, 342, 352-356.

Feeney, D. M., Rodriguez, M. A., Hovda, D. A., \& Boyeson, M. G. (1984). Remote functional depression of glucose metabolism after cortical injury is altered by amphetamine and haloperidol. Society for Neuroscience Abstracts, 10, 67.

Feeney, D. M., \& WeIr, C. S. (1979). Sensory neglect after lesions of the substantia nigra or lateral hypothalamus: Differential severity and recovery of function. Brain Research, 178, 329-346. 
Felten, D. L., Hallman, H., \& Jonsson, G. (1982). Evidence for a neurotrophic role of noradrenaline neurons in the postnataldevelopment of rat cerebral cortex. Journal of Neurocytology, 11, 119-135.

Finger, S., \& STEIN, D. G. (1982). Brain damage and recovery: Research and clinical perspectives. New York: Academic Press.

Foote, S. L., Bloom, F. E., \& Aston-Jones, G. (1983). Nucleus locus ceruleus: New evidence of anatomical and physiological specificity. Physiological Review, 63, 844-914.

FreY, K. A., \& AGRANOFF, B. W. 1983). Barbituate-enhanced detection of brain lesions by carbon-14-labeled 2-deoxyglucose autoradiography. Science, $\mathbf{2 1 9}, 879-881$.

Glassman, R. B. (1970). Contralateral and ipsilateral transfer of a cutaneous discrimination in normal and callosum sectioned cats. Journal of Comparative \& Physiological Psychology, 70, 470-475.

Glassman, R. B., \& Malamut, B. L. (1976). Recovery from electroencephalographic slowing and reduced evoked potentials after somatosensory cortical damage in cats. Behavioral Biology, 17, 333-354.

GuICK, S. D. (1974). Changes in drug sensitivity and mechanisms of functional recovery following brain damage. In D. G. Stein, J. J. Rosen, \& N. Butters (Eds.), Plasticity and recovery of function in the central nervous sysem (pp. 339-372). New York: Academic Press.

Glick, S. D., \& Zimmerberg, B. (1978). Pharmacological modification of brain lesion syndromes. In S. Finger (Ed.), Recovery from brain damage: Research and theory (pp. 281-293). New York: Plenum Press.

Greendyke, R. M., Schuster, D. B., \& Wooton, J. A. (1984). Propranolol in the treatment of assaultive patients with organic brain disease. Journal of Clinical Psychopharmacology, 4, 282-285.

Hovda, D. A., \& FeEnEY, D. M. (1984). Amphetamine with experience promotes recovery of locomotor function after unilateral frontal cortex injury in the cat. Brain Research, 298, 358-361.

HovDA, D. A., \& FEENEY, D. M. (1985). Haloperidol blocks amphetamine induced recovery of binocular depth perception after bilateral visual cortex ablation in cat. Proceedings of the Western Pharmacological Society, 28, 209-211.

Hovda, D. A., Feeney, D. M., Salo, A. A., \& Boyeson, M. G. (1983). Phenoxybenzamine but not haloperidol reinstates all motor and sensory deficits in cats fully recovered from sensorimotor cortex ablations. Society for Neuroscience Abstracts, 9, 1002.

Hovda, D. A., Sutton, R. L., \& Feeney, D. M. (1985). Asymmetry of bilateral visual cortex lesions affect amphetamine's ability to produce recovery of depth perception. Society for Neuroscience Abstracts, 11, 1016.

Jonason, K. R., Lauber, S. M., Robbins, M. J., Meyer, P. M., \& MEYER, D. R. (1970). Effects of amphetamine upon relearning pattern and black-white discriminations following neocortical lesions in rats. Journal of Comparative \& Physiological Psychology, 73, 47-55.

Kasamatsu, T., Pettigrew, J. D., \& Ary, M. (1981). Cortical recovery from effects of monocular deprivation: Acceleration with norepinephrine and suppression with 6-hydroxydopamine. Journal of Neurophysiology, 45, 254-266.

Kasamatsu, T., Watabe, K., Scholler, E., \& Heggelund, P. (1983). Restoration of neuronal plasticity in cat visual cortex by electrical stimulation of the locus coeruleus. Society for Neuroscience Abstracts, 9, 911.

Kaye, M., Mitchell, D. E., \& Cynader, M. (1981). Selective loss of binocular depth perception after ablation of cat visual cortex. $\mathrm{Na}$ ture, 293, 60-62.

KEMPINSKY, W. H. (1954). Steady potential gradients in experimental cerebral vascular occlusion. Electroencephalography \& Clinical Neurophysiology, 6, 375-388.

KEMPINSKY, W. H. (1956). Spatially remote effects of focal brain injury: Relation to diaschisis. Transcripts of the American Neurological Association, 81, 79-83.

KEMPINSKY, W. H. (1958). Experimental study of distant effects of acute focal brain injury. Archives of Neurology \& Psychiatry, 79, 376-389.

Kogure, K., Scheinberg, P., Matsumoto, A., Busto, R., \& ReinMUTH, O. M. (1975). Catecholamines in experimental brain ischemia. Archives of Neurology, 32, 21-24.
Kurshner, M., Alavi, A., Reivich, M., Dann, R., Burke, A., \& RoBinson, G. (1984). Contralateral cerebellar hypometabolism following cerebral insult: A positron emission tomographic study. Annals of Neurology, 15, 425-434.

LaManna, J. C., Harik, S. I., Light, A. I., \& Rosenthal, M. (1981). Norepinephrine depletion alters cerebral oxidative metabolism in the 'active' state. Brain Research, 204, 87-101.

LIPPER, S., \& TUCHMAN, M. M. (1976). Treatment of chronic posttraumatic organic brain syndrome with dextroamphetamine: First reported case. Journal of Nervous \& Mental Diseases, 162, 366-371.

MACHT, M. B. (1950). Effects of d-amphetamine on hemi-decorticate, decorticate, and decerebrate cats. American Journal of Physiology, 163, 731-732.

Maling, H. M., \& Acheson, G. H. (1946). Righting and other postural activity in low decerebrate and in spinal cats after d-amphetamine. Journal of Neurophysiology, 9, 379-386.

Markowitsch, H. J., \& Pritzel, M. (1978). Von Monakow's diaschisis concept: Comment on West et al. Behavioral Biology, 22, 411-412.

Marotta, R. F., Logan, N., Potegal, M., Glusman, M., \& GarDNER, E. L. (1977). Dopamine agonists induce recovery from surgicallyinduced septal rage. Nature, 269, 513-515.

McGraw, C. P., Pashyan, A. G., \& Wendell, O. T. (1976). Cerebral infarction in the Mongolian gerbil exacerbated by phenoxybenzamine treatment. Stroke, 7, 485-488.

MEYER, D. R., \& BEATTIE, M. S. (1977). Some properties of substrates of memory. In L. H. Miller, C. A. Sandman, \& A. J. Kastin (Eds.), Neuropeptide influences on the brain and behavior (pp. 145-162). New York: Raven Press.

Meyer, J. S., Miyakawa, Y., Welch, K. M. A., Itoh, Y., Ishihara, N., Chabi, E., Nell, J., Bartosh, K., \& Ericsson, A. D. (1976). Influence of adrenergic receptor blockade on circulatory and metabolic effects of disordered neurotransmitter function in stroke patients. Stroke, 7, 158-167.

Meyer, P. M., Horel, J. A., \& Meyer, D. R. (1963). Effects of d,1amphetamine upon placing responses in neodecorticate cats. Journal of Comparative \& Physiological Psychology, 56, 402-404.

MEYER, P. M., \& MEYER, D. R. (1982). Memory, remembering, and amnesia. In R. L. Isaacson, \& N. E. Spear (Eds.), The expression of knowledge (pp. 179-212). New York: Plenum.

Moore, R. Y., \& Bloom, F. E. (1979). Central catecholamine neuron systems: Anatomy and physiology of the norepinephrine and epinephrine systems. Annual Review of Neuroscience, 2, 113-168.

Nakamura, S., \& Iwama, K. (1975). Antidromic activation of the rat locus coeruleus neurons from hippocampus, cerebral and cerebellar cortices. Brain Research, 99, 372-376.

Ögren, S. O., ARCher, T., \& Ross, S. B. (1980). Evidence for a role of the locus coeruleus noradrenaline system in learning. Neuroscience Letters, 20, 351-356.

OLSON, L., \& FUXE, K. (1971). On the projections from the locus coeruleus noradrenaline neurons: The cerebellar innervation. Brain Research, 28, 165-171.

O'Shea, L., SaAri, M., Pappas, B., Ings, R., \& Stange, K. (1968). Neonatal 6-hydroxydopamine attenuates the neural and behavioral effects of enriched rearing in the rat. European Journal of Pharmacology, 92, 43-47.

PAPPIUS, H. M., \& Wolfe, L. S. (1983). Effects of indomethacin and ibuprofen on cerebral metabolism and blood flow in traumatized brain. Journal of Cerebral Blood Flow \& Metabolism, 3, 448-459.

Parnavelus, J. G., \& Blue, M. E. (1982). The role of the noradrenergic system on the formation of synapses in the visual cortex of the rat. Developmental Brain Research, 3, 140-144.

Patronas, N. J., Chiro, G. D., Smith, B. H., De la Paz, R., Brooks, R. A., Milam, H. L., Kornblith, P. L., Bairamian, D., \& MANSI, L. (1984). Depressed cerebellar glucose metabolism in supratentorial tumors. Brain Research, 291, 93-101.

Pittman, J. C., Feeney, D. M., \& Spiker, M. D. (1976). Irritation and depression of single neurons near an electrolytic lesion. Society for Neuroscience Abstracts, 2, 831.

Porch, B., Wyckes, J., \& FeEney, D. M. (1985). Haloperidol, thiazides and some antihypertensives slow recovery from aphasia. Society for Neuroscience Abstracts, 11, 52. 
Reinstein, D. K., Isaacson, R. L., \& DunN, A. J. (1979). Regional changes in 2-deoxyglucose uptake after neocortical and hippocampal destruction. Brain Research, 175, 392-397.

Ritchie, G. D., Meyer, P. M., \& Meyer, D. R. (1976). Residual spatial vision of cats with lesions of the visual cortex. Experimental Neurology, 53, 227-253.

Robinson, R. G. (1979). Differential behavioral and biochemical effects of right and left hemispheric cerebral infarction in the rat. Science, 205, 707-710.

Robinson, R. G., \& Bloom, F. E. (1977). Pharmacological treatment following experimenta! cerebral infarctions: Implications for understanding psychological symptoms of human stroke. Biological Psychiatry, 12, 669-680.

Robinson, R. G., \& Coyle, J. T. (1979). Lateralization of catecholaminergic and behavioral response to cerebral infarction in the rat. Life Sciences, 24, 943-950.

Robinson, R. G., \& Coyle, J. T. (1980). The differential effect of right versus left hemispheric cerebral infarction on catecholamines and behavior in the rat. Brain Research, 188, 63-78.

Robinson, R. G., Shoemaker, W. J., \& Schlump, M. (1980). Time course of changes in catecholamines following right hemisphere cerebral infarction in the rat. Brain Research, 181, 202-208.

Robinson, R. G., Shoemaker, W. J., Schlumpf, M., Valk, T., \& BLoom, F. E. (1975). Effect of experimental cerebral infarction in rat brain on catecholamines and behavior. Nature, 255, 332-334.

Room, P., Postema, F., \& KorF, J. (1981). Divergent axon collaterals of rat locus coeruleus neurons: Demonstration by a fluorescent double labeling technique. Brain Research, 221, 219-230.

Ross, R. A., JoH, T. H., \& REIS, D. J. (1975). Reversible changes in accumulation and activities of tyrosine hydroxylase and dopamineB-hydroxylase in neurons of locus coeruleus during the retrograde reaction. Brain Research, 92, 57-72.

Savaki, H. E., Graham, D. I., Grome, J. J., \& McCulloch, J. (1984). Functional consequences of unilateral lesion of the locus coeruleus: A quantitative $\left[{ }^{14} \mathrm{C}\right] 2$-deoxyglucose investigation. Brain Research, 292, 239-249.

Schwartz, W. J., Sharp, F. R., Ginn, R. H., \& Evarts, E. V. (1976). Lesions of ascending dopaminergic pathways decrease forebrain glucose uptake. Nature, 261, 155-157.

Sechzer, J. A., ERvin, G. N., \& SMith, G. P. (1973). Loss of visual placing in rats after lateral hypothalamic microinjections of 6hydroxydopamine. Experimental Neurology, 41, 723-737.

Smith, G. R., TAYLOR, C. W., \& Linkous, P. (1974). Haloperiodol versus thiroidazine for treatment of psychogeriatric patients: Doubleblind clinical trial. Psychosomatics, 15, 134-138.
Sokoloff, L., Reivich, M., Kennedy, C., Des Rosiers, M. H., Patlak, C. S., Pettigrew, K. D., Sakurada, O., \& Shinohara, M. (1977). The $\left[{ }^{14} \mathrm{C}\right]$ deoxyglucose method for the measurement of local cerebral glucose utilization: Theory, procedure, and normal values in the conscious and anesthetized albino rat. Journal of Neurochemistry, 28, 897-916.

STEINDLER, D. A. (1981). Locus coeruleus neurons have axons that branch to the forebrain and cerebellum. Brain Research, 223, 367-373.

Sutton, R. L., Hovda, D. A., \& FeEney, D. M. (1984). Multiple doses of d-amphetamine accelerate recovery of locomotion following bilateral frontal cortex injury in cat. Society for Neuroscience Abstracts, 10, 67.

VAN Dongen, P. A. M. (1981). The central noradrenergic transmission and the locus coeruleus: A review of the data, and their implications for neurotransmission and neuromodulation. Progress in Neurobiology, 16, 117-143.

von Monakow, C. (1969). The localization in the cerebrum and the loss of function by cortical damage (Translated and excerpted by G. Harris). In K. H. Pribram (Ed.), Brain and behavior: Vol. 1. Mood states and mind (pp. 27-37). Baltimore: Penguin. (Original work published 1914)

Watson, M., \& McElligotr, J. G. (1984). Cerebellar norepinephrine depletion and impaired acquisition of specific locomotor tasks in rats. Brain Research, 296, 129-138.

Wendlandt, S., \& File, S. E. (1979). Behavioral effects of lesions of the locus ceruleus noradrenaline system combined with adrenalectomy. Behavioral \& Neural Biology, 26, 189-201.

WEST, J. R. (1978). The concept of diaschisis: A reply to Markowitsch and Pritzel. Behavioral Biology, 22, 413-416.

West, J. R., Deadwyler, S. A., Cotman, C. W., \& Lynch, G. S. (1976). An experimental test of diaschisis. Behavioral Biology, 18, 419-425.

Zervas, N. T., Hori, H., Negora, M., Wurtman, R. J., Larin, R., \& LAVYNE, M. H. (1974). Reduction of brain dopamine following experimental cerebral ischemia. Nature, 247, 283-284.

\section{NOTE}

1. Additional evidence of a role for NE in brain injury was recently reported by Blomqvist, Lindvall, and Wieloch (1985). These authors report that bilateral lesion of the LC increases hippocampal neuronal necrosis induced by cerebral ischemia. (Note added in proof)

(Received for publication August 16, 1985; revision accepted for publication October 20,1985 .) 